\title{
OnabotulinumtoxinA muscle injection patterns in adult spasticity: a systematic literature review
}

\author{
Luba Nalysnyk ${ }^{1 *}$, Spyridon Papapetropoulos ${ }^{2}$, Philip Rotella ${ }^{3}$, Jason C Simeone ${ }^{3}$, Katharine E Alter ${ }^{4,5}$ \\ and Alberto Esquenazi ${ }^{6}$
}

\begin{abstract}
Background: OnabotulinumtoxinA has demonstrated significant benefit in adult focal spasticity. This study reviews the injection patterns (i.e., muscle distribution, dosing) of onabotulinumtoxinA for treatment of adult spasticity, as reported in published studies.

Methods: A systematic review of clinical trials and observational studies published between 1990 and 2011 reporting data on muscles injected with onabotulinumtoxinA in adult patients treated for any cause of spasticity.

Results: 28 randomized, 5 nonrandomized, and 37 single-arm studies evaluating 2,163 adult patients were included. The most frequently injected upper-limb muscles were flexor carpi radialis (64.0\% of patients), flexor carpi ulnaris (59.1\%), flexor digitorum superficialis (57.2\%), flexor digitorum profundus (52.5\%), and biceps brachii (38.8\%). The most frequently injected lower-limb muscles were the gastrocnemius (66.1\% of patients), soleus (54.7\%), and tibialis posterior (50.5\%). The overall dose range reported was 5-200 U for upper-limb muscles and 10-400 U for lower-limb muscles.

Conclusions: The reviewed evidence indicates that the muscles most frequently injected with onabotulinumtoxinA in adults with spasticity were the wrist, elbow, and finger flexors and the ankle plantar flexors. OnabotulinumtoxinA was injected over a broad range of doses per muscle among the studies included in this review, but individual practitioners should be mindful of local regulatory approvals and regulations.
\end{abstract}

Keywords: Botulinum toxin, OnabotulinumtoxinA, Spasticity, Muscles, Injection patterns

\section{Background}

Spasticity, a phenomenon associated with the upper motor neuron syndrome, was defined by James W. Lance as "a motor disorder characterized by a velocity-dependent increase in tonic stretch reflex (muscle tone) with exaggerated tendon jerks, resulting from hyper-excitability of the stretch reflex as one component of the upper motor neuron syndrome" [1].

The causes of spasticity are heterogeneous. While spasticity following stroke is common, spasticity can also occur in adults following traumatic brain injury, multiple sclerosis, spinal cord injury, and, on some occasions, degenerative central nervous system disorders [2,3]. Spasticity is often classified according to the distribution of body

\footnotetext{
* Correspondence: Inalysnyk@aol.com

${ }^{1}$ Epidemiology \& Database Analytics, United BioSource Corporation, Lexington, MA, USA

Full list of author information is available at the end of the article
}

regions affected, which may be focal, regional, or generalized $[4,5]$. Focal spasticity affects an isolated body part such as the elbow or foot, whereas regional spasticity can affect an entire limb and generalized spasticity affects multiple body areas. Topographical spasticity patterns vary with different etiologies. The distribution of spasticity is important to identify because it has treatment implications [6].

Spasticity-related muscle dysfunction is characterized by muscle hyperactivity/hypertonicity, motor weakness, and, in progressed cases, contracture of adjacent soft tissue $[7,8]$. Substantial evidence demonstrates that spasticity has a negative impact on patients, causing impairment (e.g., pain, pressure sores, contractures), activity limitation, dependence on caregivers, restriction of participation in social and family life, and decreased overall quality of life [9-11].

Management of spasticity can vary from patient to patient, typically is customized to individual patient needs, 
and includes a multidisciplinary effort with cooperation and participation of specialists, such as a physiatrist or neurologist, nurses, physical therapists, caregivers, and the patients themselves [12]. Numerous treatments are used to reduce spasticity. Botulinum neurotoxin (BoNT) injections are employed as a focal antispastic agent, usually as part of a broader rehabilitation regimen [4]. In the development of an overall treatment plan, consideration should be given to the treatment goals, including the balance between reduction of spastic hypertonia and preservation of residual motor strength and function [13].

In the United States, there are four botulinum toxin products approved for various indications. Three are serotype A (onabotulinumtoxinA [BOTOX ${ }^{\oplus}$, Allergan Inc., Irvine, CA, USA]; abobotulinumtoxinA [Dysport ${ }^{\oplus}$, Ipsen, Paris, France]; and incobotulinumtoxinA [Xeomin ${ }^{\oplus}$, Merz Pharmaceuticals GmbH, Frankfurt, Germany]), and one is serotype B (rimabotulinumtoxinB [Myobloc ${ }^{\circ} /$ Neurobloc $^{\oplus}$, Solstice Neurosciences, San Francisco, CA, USA]). Each differs in molecular structure, formulation, and clinical profile. There is no potency reference standard that is applicable for BoNTs, and each formulation of BoNT is different. Therefore, the units of activity are specific to each product and are not interchangeable with those of any other BoNT [14]. Currently, only onabotulinumtoxinA is approved by the US Food and Drug Administration for the treatment of upper-limb spasticity in adults [15].

Although many studies have been published with regard to the efficacy, safety, and effectiveness of onabotulinumtoxinA for the treatment of spasticity, there is no comprehensive analysis of the literature available that examines the injection patterns of onabotulinumtoxinA. It is therefore the aim of this systematic review to summarize the specific topography of injected muscles, the mean dose of injections per muscle, and the range of doses among patients treated with onabotulinumtoxinA for adult spasticity. It should be noted that "injection patterns" is a broad term that can also include regional topography of injections and techniques for isolating muscles for injection; for the purposes of this review, the term "injection patterns" refers only to the above-mentioned topics of specific topography of injected muscles and dosing.

\section{Methods}

\section{Literature search}

A prospective protocol outlining the methodology of this systematic review was developed and followed. A literature search was performed to identify all English-language clinical trials or observational studies (prospective or retrospective) of onabotulinumtoxinA injections used for the treatment of patients with adult spasticity published since 1990. The methods used to perform this review involved both electronic and manual components, and followed established "best practice" guidelines for systematic review research [16,17]. Searches in MEDLINE and EMBASE were conducted for all studies of BoNT used for treatment of adult spasticity and published between January 1985 and April 2011 to identify any studies of onabotulinumtoxinA. The combination of the following search terms was used: spastic, spasticity, spasm, hyperreflexia, hypertonia, hemiplegia, paralysis. For details of the specific search terms used, please see Additional file 1. The electronic searches were further supplemented by a manual search of the reference lists of all accepted studies, as well as the reference lists of recent relevant reviews and meta-analyses.

\section{Study identification}

Animal or in vitro studies, studies performed in pediatric populations, and studies reporting treatment with BoNT products other than onabotulinumtoxinA were excluded. The full-text publications of accepted abstracts were reviewed to satisfy all of the following inclusion criteria, regardless of spastic pattern or origin: adult patients with spasticity, treated with onabotulinumtoxinA, and available data on which individual muscles in the upper and/or lower limbs were injected with onabotulinumtoxinA. Included studies were not required to report the number of patients injected or dose parameters for specific muscles, although this data was captured when reported. The agreement of two investigators was required to accept or reject any articles during the review process.

\section{Data extraction and synthesis}

Data elements of interest from each accepted study were extracted to a data extraction form. Extracted information included study-level (e.g., year of publication, geographic region, and study design), patient-level (e.g., sample size, mean age, and gender distribution), and treatment-level (e.g., mean dose and site of onabotulinumtoxinA injection) characteristics. Whenever possible, subgroup data were extracted by spasticity diagnosis from studies enrolling patients with spasticity due to various causes. All injected muscles were considered as reported, regardless of the spastic pattern or origin of spasticity in individuals or patient populations. For studies with patient samples that also included patients treated with other BTX-A formulations, only patients treated with onabotulinumtoxinA were considered. One investigator extracted the data from each study, and a second investigator independently reviewed the extracted data for completeness and accuracy against the original study. Efficacy, safety, and patient-reported outcomes were not assessed in this review and therefore not captured.

Linked studies, which are multiple studies that report outcomes from the same patient sample, in part or in total, were identified during the screening and data extraction 
phases. When linked studies were identified, only data from the largest, most recent, or most complete report were extracted. However, relevant data from earlier and smaller reports were also used if the report presented pertinent subgroup data not presented in the larger, more complete report. Therefore, all linked studies were considered to be included studies, though each set of linked studies was only counted as one study to avoid doublecounting patients.

Descriptive statistics were applied to summarize study-, patient-, and treatment-level data. Information on injected muscles and corresponding onabotulinumtoxinA doses was summarized for individual muscles and muscle groups for upper and lower limbs. Studies reporting on patients treated with onabotulinumtoxinA for both upperand lower-limb spasticity were included in both respective categories of muscles. Some studies had multiple treatment arms where all patients received onabotulinumtoxinA (with varying doses, patient characteristics, or supplemental treatments such as physiotherapy). All tables include counts of the number of studies (k), the number of onabotulinumtoxinA treatment arms (t), and the number of patients $(\mathrm{n})$ that match a given characteristic, as well as the total number of patients in treatment arms that reported the characteristic $(\mathrm{N})$. To calculate the frequency of injections in individual muscles, the number of all patients/limbs treated with onabotulinumtoxinA in upper limbs or lower limbs, respectively, was used as a denominator, while the numerator for each muscle injected was the number of patients/limbs injected in that particular muscle. Mean doses per muscle were calculated as a mean of all study means, weighted by the number of patients who received injections into each muscle in each study. Note that mean dose may not necessarily account for the full range of doses administered, since dose range was reported in more studies than was mean dose and mean dose could only be tabulated for the subset of studies that explicitly reported it (see semitendinosus, for example). Descriptive summary data, including frequencies of muscles injected, are presented for patients with upper-limb spasticity and lower-limb spasticity, regardless of spasticity origin. Categorical outcomes are presented as proportions, and continuous outcomes are presented using means and ranges.

Information on injected muscles was also analyzed separately by the origin of spasticity (i.e., stroke, traumatic brain injury, spinal cord injury, or multiple sclerosis) using the same methods as described above. These subgroup analyses are presented in Additional files 2, 3, 4 and 5.

Since the focus of this review was not on efficacy and safety, the risk of bias within individual studies was not assessed.

\section{Results}

\section{Study attrition}

The entire literature search, including manual bibliography checks, identified 2,761 citations, not including duplicate citations from the various sources. The vast majority of these citations were rejected during abstract screening. Corresponding full papers for 135 abstracts were retrieved for further review and screened against the protocol-specified inclusion criteria. Of the full papers retrieved, 61 were rejected at the full-text review or during data extraction, leaving 74 publications. Among these 74, four pairs of linked publications were identified, from institutions in Turkey [18,19], Italy [20,21], Taiwan [22,23], and France $[24,25]$. Since only the most informative study was counted from each pair of linked publications, a total of 70 primary studies [2,18,20,23,25-90] pertaining to the treatment of adult spasticity with onabotulinumtoxinA were analyzed. The most common rejection reasons were reviews, not onabotulinumtoxinA treatment, or BoNT formulation not specified. A detailed flow diagram of the study attrition is presented in Figure 1.

\section{Study characteristics}

The majority of the 70 primary studies (comprising 2,163 patients) were conducted in Europe $(n=35)$ or North America ( $\mathrm{n}=18$ ), while nine studies were completed in Asia and eight in other geographic locations (Additional file 6). Nearly all included studies (97\%) were published since 1995 . There were 28 randomized clinical trials, five nonrandomized clinical trials, and 37 singlearm, uncontrolled case series. Sixty-seven studies (96\%) were conducted prospectively. Most studies $(\mathrm{n}=33$ ) reported only treatment of upper-limb spasticity, 11 studies reported treatment of both upper- and lowerlimb spasticity, and 26 studies evaluated patients with lower-limb spasticity. In total, data on upper-limb spasticity was presented in 44 studies comprising 1,670 patients, of which 788 (47.1\%) had frequency data reported for onabotulinumtoxinA injections in upper-limb muscles. Data on lower-limb spasticity was reported in 37 studies comprising 1,347 patients, of which 602 (44.7\%) had frequency data reported for onabotulinumtoxin A injections in lower-limb muscles. Among the 70 studies (92 treatment arms), the frequency of injections into individual muscles was reported in 55 studies (77 treatment arms), and mean dose per injected muscle was reported in 46 studies (63 treatment arms).

\section{Baseline patient characteristics}

Table 1 presents the summary of baseline characteristics of adult patients treated with onabotulinumtoxinA for upper- or lower-limb spasticity. Among the large majority of studies reporting gender distribution of enrolled patients, males predominated $(60.3 \%$ and $58.3 \%$ for upper- 


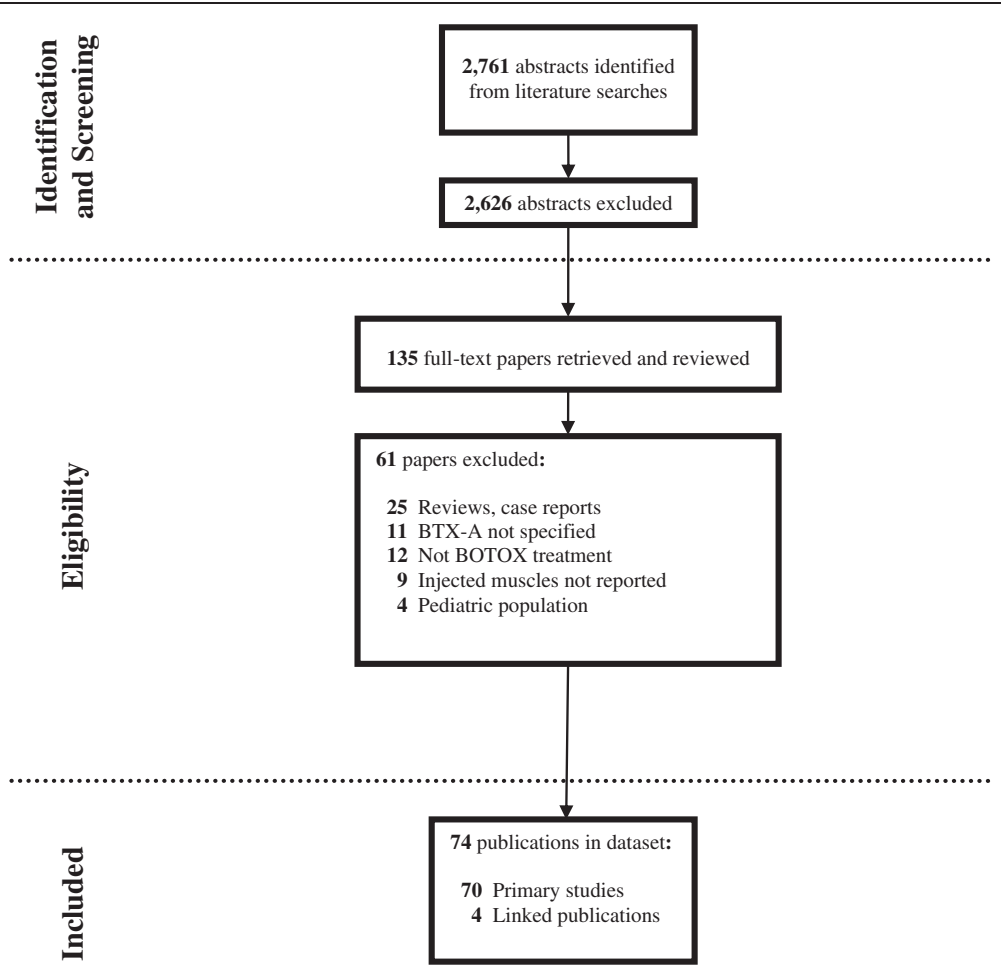

Figure 1 Flow diagram of study attrition.

and lower-limb spasticity, respectively). Stroke was the most commonly reported cause of upper- and lower-limb spasticity $(66.2 \%$ and $62.1 \%$, respectively), while strokes or traumatic brain injuries were combined in several studies as the cause of spasticity in $6.4 \%$ (upper limb) and 5.2\% (lower limb) of patients. Traumatic brain injury, multiple sclerosis, and spinal cord injuries were reported to be the cause of spasticity in approximately $7 \%$ of all patients combined, while in $22.7 \%$ of all patients various causes of spasticity were reported. The mean age of patients with

Table 1 Baseline patient characteristics

\begin{tabular}{|c|c|c|c|c|c|c|c|c|}
\hline \multirow[t]{2}{*}{ Characteristic } & \multicolumn{4}{|c|}{ Upper-limb spasticity } & \multicolumn{4}{|c|}{ Lower-limb spasticity } \\
\hline & $\mathbf{k}$ & $\mathrm{t}$ & $n / N$ & Frequency (\%) & k & $\mathbf{t}$ & $n / N$ & Frequency (\%) \\
\hline Total & 44 & $59^{*}$ & 1,670 & - & 37 & 47 & 1,347 & - \\
\hline Gender & 36 & 47 & 1,464 & 100.0 & 31 & 40 & 1,200 & 100.0 \\
\hline Male & 36 & 47 & $883 / 1,464$ & 60.3 & 31 & 40 & $699 / 1,200$ & 58.3 \\
\hline Female & 36 & 47 & $581 / 1,464$ & 39.7 & 31 & 39 & $501 / 1,200$ & 41.8 \\
\hline Spasticity origin & 44 & 59 & 1,670 & 100.0 & 37 & 47 & 1,347 & 100.0 \\
\hline Stroke only & 24 & 31 & $1,105 / 1,670$ & 66.2 & 16 & 21 & $837 / 1,347$ & 62.1 \\
\hline Stroke/Traumatic brain injury & 6 & 8 & $107 / 1,670$ & 6.4 & 3 & 3 & $70 / 1,347$ & 5.2 \\
\hline Traumatic brain injury only & 1 & 2 & $21 / 1,670$ & 1.3 & 1 & 1 & $7 / 1,347$ & 0.5 \\
\hline Multiple sclerosis & 2 & 3 & $43 / 1,670$ & 2.6 & 5 & 6 & $80 / 1,347$ & 5.9 \\
\hline Spinal cord injury & 1 & 1 & $28 / 1,670$ & 1.7 & 1 & 2 & $36 / 1,347$ & 2.7 \\
\hline \multirow[t]{2}{*}{ Mixed/Other } & 10 & 14 & $366 / 1,670$ & 21.9 & 11 & 14 & $317 / 1,347$ & 23.5 \\
\hline & k & $\mathbf{t}$ & Mean & Range of means & k & $\mathbf{t}$ & Mean & Range of means \\
\hline Age (years) & 39 & 53 & 51.7 & $26-66.3$ & 35 & 45 & 49.9 & $26-66.3$ \\
\hline Time since onset (months) & 31 & 43 & 46.9 & $4.7-120$ & 26 & 34 & 53.6 & $0.35-218.4$ \\
\hline
\end{tabular}

$k=$ Number of studies, $t=$ Number of treatment arms, $n=$ Number of patients with this characteristic, $N=$ Total number of patients in treatment arms reporting characteristic. *The 44 studies that reported on patients with upper-limb spasticity had a total of 59 onabotulinumtoxinA treatment arms; however, only 58 of these arms consisted of at least 1 patient with upper-limb spasticity, as shown in Table 2. 
Table 2 Dose range, muscle distribution, and mean dose of onabotulinumtoxinA injections in upper limbs

\begin{tabular}{|c|c|c|c|c|c|c|c|c|c|c|c|}
\hline \multirow[t]{2}{*}{ Muscles } & \multicolumn{3}{|c|}{$\begin{array}{l}\text { All studies (44 studies, } \\
58 \text { treatment arms) }\end{array}$} & \multicolumn{4}{|c|}{$\begin{array}{l}\text { Studies reporting number of patients injected } \\
\text { (33 studies, } 46 \text { treatment arms) }\end{array}$} & \multicolumn{4}{|c|}{$\begin{array}{l}\text { Studies reporting mean do } \\
\text { (26 studies, } 39 \text { treatment ar }\end{array}$} \\
\hline & k & $t$ & Dose range $(U)$ & k & $t$ & $n / N$ & Frequency (\%) & k & $t$ & $\mathrm{n}$ & Mean dose \\
\hline \multicolumn{12}{|l|}{ Shoulder } \\
\hline Infraspinatus & 2 & 2 & 60 & 2 & 2 & 18/788 & 2.3 & 1 & 1 & 2 & 60.0 \\
\hline Shoulder adductors** & 1 & 1 & 30-100 & 1 & 1 & $8 / 788$ & 1.0 & 1 & 1 & 8 & 55.6 \\
\hline Deltoid & 1 & 1 & $N R$ & 1 & 1 & $1 / 788$ & 0.1 & 0 & 0 & 0 & NR \\
\hline Latissimus dorsi $^{\dagger}$ & 1 & 1 & 50-100 & 1 & 1 & $14 / 788$ & 1.8 & 1 & 1 & 14 & 66.1 \\
\hline Levator scapulae & 1 & 1 & $N R$ & 1 & 1 & $1 / 788$ & 0.1 & 0 & 0 & 0 & $N R$ \\
\hline Paraspinous & 1 & 1 & 100 & 1 & 1 & $1 / 788$ & 0.1 & 1 & 1 & 1 & 100.0 \\
\hline Pectoralis & 7 & 7 & $30-100$ & 5 & 5 & 39/788 & 4.9 & 3 & 3 & 22 & 67.3 \\
\hline Rhomboid & 1 & 1 & 50 & 1 & 1 & $8 / 788$ & 1.0 & 1 & 1 & 8 & 50.0 \\
\hline Sternocleidomastoid & 1 & 1 & $N R$ & 1 & 1 & $2 / 788$ & 0.3 & 0 & 0 & 0 & NR \\
\hline Subscapularis & 2 & 2 & 100 & 2 & 2 & $26 / 788$ & 3.3 & 1 & 1 & 10 & 100.0 \\
\hline Teres major & 1 & 1 & 40 & 1 & 1 & $1 / 788$ & 0.1 & 1 & 1 & 1 & 40.0 \\
\hline Trapezius & 2 & 2 & 60 & 2 & 2 & $3 / 788$ & 0.4 & 1 & 1 & 1 & 60.0 \\
\hline Triceps brachii & 5 & 6 & 50-100 & 4 & 4 & 10/788 & 1.3 & 3 & 3 & 9 & 73.6 \\
\hline \multicolumn{12}{|l|}{ Forearm } \\
\hline Extensor carpi radialis & 3 & 4 & $5-50$ & 3 & 4 & $6 / 788$ & 0.8 & 2 & 3 & 4 & 17.5 \\
\hline Extensor carpi ulnaris & 1 & 2 & $5-10$ & 1 & 2 & $3 / 788$ & 0.4 & 1 & 2 & 3 & 6.7 \\
\hline Extensor digitorum & 1 & 1 & $N R$ & 1 & 1 & $1 / 788$ & 0.1 & 0 & 0 & 0 & NR \\
\hline Pronator quadrates & 2 & 2 & 25 & 1 & 1 & $1 / 788$ & 0.1 & 0 & 0 & 0 & $N R$ \\
\hline Pronator teres & 14 & 16 & $10-90$ & 10 & 11 & $96 / 788$ & 12.2 & 6 & 7 & 65 & 33.3 \\
\hline Supinator & 1 & 1 & 5 & 1 & 1 & $1 / 788$ & 0.1 & 1 & 1 & 1 & 5.0 \\
\hline \multicolumn{12}{|l|}{ Elbow flexors } \\
\hline Biceps brachii* & 30 & 40 & $25-200$ & 19 & 27 & $306 / 788$ & 38.8 & 16 & 24 & 263 & 95.4 \\
\hline Brachialis & 10 & 12 & 20-100 & 4 & 4 & $27 / 788$ & 3.4 & 1 & 1 & 1 & 60.0 \\
\hline Brachioradialis & 17 & 20 & $15-200$ & 9 & 11 & 104/788 & 13.2 & 7 & 9 & 75 & 41.1 \\
\hline \multicolumn{12}{|l|}{ Wrist flexors } \\
\hline Flexor carpi radialis* & 34 & 45 & $5-100$ & 24 & 34 & $504 / 788$ & 64.0 & 18 & 28 & 433 & 49.0 \\
\hline Flexor carpi ulnaris* & 34 & 45 & $5-100$ & 23 & 33 & $466 / 788$ & 59.1 & 18 & 28 & 420 & 46.7 \\
\hline Palmaris longus & 3 & 3 & $20-25$ & 2 & 2 & $8 / 788$ & 1.0 & 1 & 1 & 4 & 23.8 \\
\hline Wrist flexors $^{\ddagger}$ & 1 & 1 & $50-120$ & 1 & 1 & 20/788 & 2.5 & 1 & 1 & 20 & 72.8 \\
\hline \multicolumn{12}{|l|}{ Finger flexors } \\
\hline Finger flexors $^{\S}$ & 1 & 1 & $30-160$ & 1 & 1 & 20/788 & 2.5 & 1 & 1 & 20 & 97.8 \\
\hline Flexor digitorum profundus* & 31 & 39 & $5-120$ & 20 & 27 & $414 / 788$ & 52.5 & 16 & 23 & 361 & 42.0 \\
\hline Flexor digitorum superficialis* & 31 & 40 & $5-150$ & 20 & 28 & $451 / 788$ & 57.2 & 16 & 24 & 386 & 50.3 \\
\hline Forearm finger flexor & 1 & 1 & 80 & 1 & 1 & $5 / 788$ & 0.6 & 1 & 1 & 5 & 80.0 \\
\hline Interossei volares & 1 & 1 & $10-15$ & 1 & 1 & $4 / 788$ & 0.5 & 1 & 1 & 4 & 11.3 \\
\hline \multicolumn{12}{|l|}{ Thumb } \\
\hline Adductor pollicis & 7 & 8 & $10-20$ & 5 & 6 & 102/788 & 12.9 & 3 & 4 & 93 & 18.9 \\
\hline Flexor pollicis brevis & 1 & 1 & $N R$ & 1 & 1 & $2 / 788$ & 0.3 & 0 & 0 & 0 & $N R$ \\
\hline Flexor pollicis longus & 20 & 24 & $10-35$ & 11 & 13 & $161 / 788$ & 20.4 & 7 & 9 & 132 & 19.0 \\
\hline Lumbricals & 3 & 4 & 30 & 2 & 2 & $4 / 788$ & 0.5 & 1 & 1 & 1 & 30.0 \\
\hline
\end{tabular}


Table 2 Dose range, muscle distribution, and mean dose of onabotulinumtoxinA injections in upper limbs

\begin{tabular}{|c|c|c|c|c|c|c|c|c|c|c|c|}
\hline \multirow[t]{2}{*}{ Muscles } & \multicolumn{3}{|c|}{$\begin{array}{l}\text { All studies (44 studies, } \\
58 \text { treatment arms) }\end{array}$} & \multicolumn{4}{|c|}{$\begin{array}{l}\text { Studies reporting number of patients injected } \\
\text { (33 studies, } 46 \text { treatment arms) }\end{array}$} & \multicolumn{4}{|c|}{$\begin{array}{l}\text { Studies reporting mean dose } \\
\text { ( } 26 \text { studies, } 39 \text { treatment arms) }\end{array}$} \\
\hline & $\mathbf{k}$ & $\mathrm{t}$ & Dose range $(\mathrm{U})$ & k & $\mathrm{t}$ & $\mathrm{n} / \mathrm{N}$ & Frequency (\%) & k & $\mathbf{t}$ & $\mathbf{n}$ & Mean dose $(U)$ \\
\hline Opponens & 1 & 1 & 10 & 0 & 0 & NR & NR & 0 & 0 & 0 & $N R$ \\
\hline Opponens pollicis & 2 & 2 & NR & 1 & 1 & $4 / 788$ & 0.5 & 0 & 0 & 0 & NR \\
\hline \multicolumn{12}{|l|}{ Other muscles } \\
\hline Other upper-limb muscles & 1 & 1 & NR & 0 & 0 & NR & NR & 0 & 0 & 0 & NR \\
\hline Upper-limb flexors & 1 & 1 & $50-150$ & 0 & 0 & NR & NR & 0 & 0 & 0 & NR \\
\hline
\end{tabular}

*Muscles currently approved in the United States for onabotulinumtoxinA injection.

**Deltoid, pectoralis major.

†Reported as "dorsalis major".

FFlexor carpi radialis, palmaris longus, flexor carpi ulnaris.

${ }^{\S}$ Flexor pollicis longus, flexor digitorum profundus, flexor digitorum superficialis.

$k=$ Number of studies, $t=$ Number of treatment arms, $n=$ Number of patients injected with onabotulinumtoxinA, $N=$ Total number of patients in treatment arms reporting number of patients injected with onabotulinumtoxinA, $N R=$ Not reported, $U=$ Units.

spasticity of the upper limb was 51.7 years versus 49.9 years for patients with spasticity of the lower limb. The mean time since disease onset was 46.9 months among patients with spasticity of the upper limb, compared to 53.6 months for patients with spasticity of the lower limb.

\section{Characteristics of onabotulinumtoxinA injections Upper-limb muscles}

The most frequently injected upper-limb muscles were wrist, finger, and elbow flexors (Table 2). The frequency of onabotulinumtoxinA injections among 788 patients with available data indicates that flexor carpi radialis $(64.0 \%$ of patients) and flexor carpi ulnaris (59.1\%) were the most commonly injected muscles, followed by flexor digitorum superficialis $(57.2 \%)$, flexor digitorum profundus (52.5\%), biceps brachii (38.8\%), and flexor pollicis longus (20.4\%). Other muscles, including those in the shoulder and forearm, were injected less frequently, ranging from $0.1 \%$ to $13.2 \%$ of patients.

Overall, the doses of onabotulinumtoxinA injected into upper-limb muscles ranged from 5-200 U among all extracted studies. The mean dose of onabotulinumtoxinA injected into the upper-limb muscles ranged from $5 \mathrm{U}$ in the wrist supinator muscle of the forearm to $100 \mathrm{U}$ injected in the paraspinous and subscapularis muscles of the shoulder. The weighted mean doses varied within muscle groups, although the overall ranges of mean doses were similar among the shoulder muscles (range: 40-100 U), elbow flexors (range: 41.1-95.4 U), wrist flexors (range: 23.8-72.8 U), and finger flexors (range: 11.3-97.8 U). Mean doses injected in the forearm (range: 5.0-33.3 U) and thumb muscles (range: 18.9-30 U) were smaller, as observed by their respective mean dose ranges.

\section{Lower-limb muscles}

Ankle plantar flexors were the most frequently injected muscles of the lower limb (Table 3). Among 602 patients injected with onabotulinumtoxin A in lower-limb muscles, $66.1 \%$ were injected in the gastrocnemius muscles. Over half of the patients were injected in the soleus $(54.7 \%)$ and the tibialis posterior (50.5\%), while $12.5 \%$ received injections in the flexor digitorum longus. Less than $10 \%$ of patients were injected in other lower-limb muscles, which ranged from $0.2 \%$ in the psoas major to $8.3 \%$ in the tibialis anterior.

The overall range of doses of onabotulinumtoxinA injected into lower-limb muscles varied greatly, from 10$400 \mathrm{U}$. Mean doses ranged from $30.0 \mathrm{U}$ in the vastus medialis to $186.9 \mathrm{U}$ in the rectus femoris. Other higher mean doses were also reported among hip adductors (range: 91.7-142.4 U), ankle plantar flexors (range: 56.8$95.2 \mathrm{U}$ ), foot flexors and extensors (range: 50.0-71.9 U), and knee flexors (range: 34.0-75.0 U). The lowest mean doses reported among lower-limb muscles were injected in toe flexors (range: 11.7-57.2 U) and knee extensors (range: 30.0-38.3 U).

\section{Discussion}

In this systematic review of the literature, we summarized publications on onabotulinumtoxinA injections in adult patients treated for upper- or lower-limb spasticity. Our goal was to review the injection and dosing patterns reported from various treatment settings including clinical trials and real-world practices, as a practical guidance manuscript of this scope is not currently available in the literature. Seventy-four studies evaluating a total of 2,163 patients were included in this review.

The reviewed evidence indicates that studies vary in terms of geography, study design, sample size, treated patient population, and onabotulinumtoxinA injection practices. The heterogeneity of treatment patterns reported in this review likely reflects real differences in topographical patterns of spasticity. However, it is probable that physician preference, individual interpretation of clinical treatment guidelines, and possibly local health care coverage regulations account for much of the variation reported here. 
Table 3 Dose range, muscle distribution, and mean dose of onabotulinumtoxinA injections in lower limbs

\begin{tabular}{|c|c|c|c|c|c|c|c|c|c|c|c|}
\hline \multirow[t]{2}{*}{ Muscles } & \multicolumn{3}{|c|}{$\begin{array}{c}\text { All studies (37 studies, } 47 \\
\text { treatment arms) } \\
\end{array}$} & \multicolumn{4}{|c|}{$\begin{array}{l}\text { Studies reporting number of patients } \\
\text { injected ( } 31 \text { studies, } 40 \text { treatment arms) }\end{array}$} & \multicolumn{4}{|c|}{$\begin{array}{l}\text { Studies reporting mean dose ( } 24 \\
\text { studies, } 29 \text { treatment arms) }\end{array}$} \\
\hline & $k$ & $t$ & Dose range $(U)$ & k & $t$ & $\mathrm{n} / \mathrm{N}$ & Frequency (\%) & k & $\mathbf{t}$ & $\mathrm{N}$ & Mean dose $(U)$ \\
\hline \multicolumn{12}{|l|}{ Hip adductors } \\
\hline Adductor longus & 4 & 4 & $50-400$ & 4 & 4 & $26 / 602$ & 4.3 & 3 & 3 & 17 & 115.9 \\
\hline Adductor magnus & 5 & 5 & $20-200$ & 5 & 5 & $26 / 602$ & 4.3 & 4 & 4 & 17 & 142.4 \\
\hline Adductor brevis & 3 & 3 & 50-100 & 3 & 3 & $12 / 602$ & 2.0 & 3 & 3 & 12 & 91.7 \\
\hline Hip adductors & 5 & 6 & $50-160$ & 3 & 3 & $32 / 602$ & 5.3 & 0 & 0 & 0 & NR \\
\hline \multicolumn{12}{|l|}{ Hip flexors } \\
\hline Iliopsoas & 2 & 2 & $40-100$ & 2 & 2 & $5 / 602$ & 0.8 & 0 & 0 & 0 & NR \\
\hline Psoas major & 1 & 1 & NR & 1 & 1 & $1 / 602$ & 0.2 & 0 & 0 & 0 & NR \\
\hline Rectus femoris & 6 & 6 & $30-200$ & 6 & 6 & $42 / 602$ & 7.0 & 4 & 4 & 32 & 186.9 \\
\hline \multicolumn{12}{|l|}{ Knee flexors } \\
\hline Biceps femoris & 6 & 6 & $30-200$ & 5 & 5 & $34 / 602$ & 5.6 & 2 & 2 & 6 & 56.7 \\
\hline Hamstrings & 1 & 1 & $50-200$ & 0 & 0 & NR & NR & 0 & 0 & 0 & NR \\
\hline Knee flexors & 1 & 2 & NR & 0 & 0 & NR & NR & 0 & 0 & 0 & NR \\
\hline Semimembranosus & 8 & 8 & $40-200$ & 6 & 6 & $41 / 602$ & 6.8 & 3 & 3 & 4 & 75.0 \\
\hline Semitendinosus & 6 & 6 & 30-200 & 4 & 4 & $42 / 602$ & 7.0 & 1 & 1 & 5 & 34.0 \\
\hline \multicolumn{12}{|l|}{ Knee extensors } \\
\hline Quadriceps & 1 & 1 & $N R$ & 0 & 0 & NR & NR & 0 & 0 & 0 & NR \\
\hline Vastus intermedius & 1 & 1 & NR & 1 & 1 & $4 / 602$ & 0.7 & 0 & 0 & 0 & NR \\
\hline Vastus lateralis & 4 & 4 & $25-60$ & 3 & 3 & $4 / 602$ & 0.7 & 2 & 2 & 3 & 38.3 \\
\hline Vastus medialis & 3 & 3 & 30 & 2 & 2 & $4 / 602$ & 0.7 & 1 & 1 & 1 & 30.0 \\
\hline \multicolumn{12}{|l|}{ Ankle plantar flexors } \\
\hline Gastrocnemius & 31 & 36 & $20-320$ & 26 & 31 & $398 / 602$ & 66.1 & 16 & 19 & 246 & 88.2 \\
\hline Gastrocnemius lateralis & 13 & 14 & $50-200$ & 12 & 13 & $164 / 602$ & 27.2 & 9 & 9 & 130 & 86.7 \\
\hline Gastrocnemius medialis & 13 & 14 & $50-200$ & 12 & 13 & $165 / 602$ & 27.4 & 9 & 9 & 131 & 86.8 \\
\hline Soleus & 25 & 28 & $40-240$ & 21 & 24 & $329 / 602$ & 54.7 & 14 & 16 & 233 & 95.2 \\
\hline Tibialis anterior & 7 & 7 & $30-150$ & 5 & 5 & $50 / 602$ & 8.3 & 2 & 2 & 37 & 56.8 \\
\hline Tibialis posterior & 24 & 29 & $20-200$ & 18 & 23 & $304 / 602$ & 50.5 & 11 & 15 & 218 & 80.7 \\
\hline \multicolumn{12}{|l|}{ Foot flexors/extensors } \\
\hline Extensor hallucis longus & 6 & 6 & $25-100$ & 5 & 5 & $22 / 602$ & 3.7 & 4 & 4 & 20 & 71.9 \\
\hline Flexor hallucis longus & 7 & 7 & $15-95$ & 7 & 7 & $33 / 602$ & 5.5 & 4 & 4 & 22 & 50.9 \\
\hline Foot flexors & 1 & 2 & NR & 0 & 0 & NR & NR & 0 & 0 & 0 & NR \\
\hline Small foot flexors & 1 & 1 & 50 & 1 & 1 & $5 / 602$ & 0.8 & 1 & 1 & 5 & 50.0 \\
\hline \multicolumn{12}{|l|}{ Toe flexors } \\
\hline Flexor digitorum longus & 10 & 12 & $20-125$ & 10 & 12 & $75 / 602$ & 12.5 & 6 & 8 & 50 & 57.2 \\
\hline Flexor digitorum brevis & 6 & 8 & $20-100$ & 5 & 7 & $25 / 602$ & 4.2 & 3 & 5 & 18 & 54.4 \\
\hline Flexor hallucis brevis & 2 & 2 & $10-15$ & 2 & 2 & $3 / 602$ & 0.5 & 2 & 2 & 3 & 11.7 \\
\hline
\end{tabular}

$k=$ Number of studies, $t=$ Number of treatment arms, $n=$ Number of patients injected with onabotulinumtoxinA, $N=$ Total number of patients in treatment arms reporting number of patients injected with onabotulinumtoxin $A, N R=$ Not reported, $U=$ Units.

Variation also exists in the injection patterns reported among patients with spasticity from different etiologies (see Additional files 3, 4, 5 and 6).

In the United States, onabotulinumtoxinA is currently indicated for the treatment of upper-limb spasticity in adult patients to reduce the severity of increased muscle tone in elbow flexors (biceps), wrist flexors (flexor carpi radialis and flexor carpi ulnaris), and finger flexors (flexor digitorum profundus and flexor digitorum sublimis). In the reviewed studies, these muscles appear to be 
commonly injected to treat upper-limb spasticity. In many studies, other upper-limb muscles were also injected, among which the brachialis, brachioradialis, pronator teres, and flexor pollicis longus were most often reported. Among lower-limb muscles, ankle plantar flexors (gastrocnemius, soleus, and tibialis posterior) were most frequently injected. Other lower-limb muscles treated with onabotulinumtoxinA included hip adductors, hip flexors, knee flexors, knee extensors, foot flexors, and toe flexors. Doses of onabotulinumtoxinA varied depending on muscle size, location of injection, severity of spasticity, and whether the injection was the first treatment or was performed taking into account the patients' responses to previous treatment.

As with any systematic literature review, there are several limitations that should be noted. First, it is important to recognize that not all studies reported detailed information on onabotulinumtoxinA injections. Some only listed muscle groups, others specified individual muscles but did not provide patient counts for injected muscles, and many studies did not report muscle data and thus were excluded from this review. In addition, onabotulinumtoxinA dose information was not reported consistently across all included studies, and thus the estimates of mean dose do not necessarily represent the full range of doses injected in specific muscles. This potentially reduces the accuracy of estimates of the frequency of muscle injection. Second, our findings might be biased by the results from clinical trials, where patients had onabotulinumtoxinA injected into prespecified muscles at specified doses. This may not accurately reflect onabotulinumtoxinA treatment practices in adult patients with spasticity in "real life". The various aims and scopes of the studies included in this review may have biased the dosage of onabotulinumtoxinA administered in each included study. However, these studies were included because the injection site and/or dosage of onabotulinumtoxinA was discussed in each and the objective of this review was to summarize data on the dose, frequency, and location of intramuscular injections published in the literature, not to review associated efficacy and safety outcomes.

Nevertheless, this literature review indicates that onabotulinumtoxinA is well studied for the treatment of adult spasticity of the upper and lower limbs.

\section{Conclusions}

Although there is a substantial body of published literature on onabotulinumtoxinA in adult spasticity, including systematic reviews and meta-analyses, no prior study, to our knowledge, has systematically summarized injection patterns. This review provides additional information for physicians on varying muscle injection distributions and dosing practices of onabotulinumtoxinA injections in adult spasticity, for both on-label and off-label muscles. These findings indicate that the wrist, elbow, finger flexors, and ankle plantar flexors were most frequently injected with onabotulinumtoxinA in adults with spasticity. The overall dose range of onabotulinumtoxinA injected was 5-200 U for upper-limb muscles and 10-400 U for lower-limb muscles. As regulatory approvals for onabotulinumtoxinA differ across countries, the patterns of injection/treatment presented here are the results of this literature search and are neither an endorsement for use nor a substitution for local regulations.

\section{Additional files}

Additional file 1: Electronic search strategy. Full, detailed description of the electronic search strategy employed.

Additional file 2: OnabotulinumtoxinA injections for stroke. Supplemental table presenting subgroup analysis of injected muscles in patients whose spasticity origin was stroke.

Additional file 3: OnabotulinumtoxinA injections for traumatic brain injury. Supplemental table presenting subgroup analysis of injected muscles in patients whose spasticity origin was traumatic brain injury.

Additional file 4: OnabotulinumtoxinA injections for spinal cord injury. Supplemental table presenting subgroup analysis of injected muscles in patients whose spasticity origin was spinal cord injury.

Additional file 5: OnabotulinumtoxinA injections for multiple sclerosis. Supplemental table presenting subgroup analysis of injected muscles in patients whose spasticity origin was multiple sclerosis.

Additional file 6: Study characteristics. Supplemental table presenting characteristics (publication year, geographic location, study design, study type, and spasticity examined) for all included studies.

\section{Abbreviation}

BoNT: Botulinum neurotoxin.

\section{Competing interests}

This research was funded by Allergan, Inc. LN was an employee of United BioSource Corporation, which has received consulting fees from Allergan, Inc., and is currently a full-time employee of Genzyme, a sanofi company. SP was a full-time employee of Allergan, Inc., and is currently a full-time employee of Pfizer Inc. PR is an employee of Evidera, which has received consulting fees from Allergan, Inc. JCS is an employee of Evidera, which has received consulting fees from Allergan, Inc. KEA has received consulting fees and participated on advisory boards for spasticity protocols for Allergan, Inc. $A E$ has received research funding and participated as research advisor for Allergan, Inc., and Ipsen.

\section{Authors' contributions}

LN was the principal investigator of this study; participated in the study design and coordination; performed the literature review, data collection, and planned statistical analysis; drafted the manuscript; and read and approved the final manuscript. SP was involved in drafting the manuscript and revising it critically for important intellectual content; and read and approved the final manuscript. PR carried out the descriptive analysis of the data, helped to draft the manuscript, and read and approved the final manuscript. JCS participated in the interpretation of the data, helped to draft the manuscript, and read and approved the final manuscript. KEA made substantial contributions to conception, design, and data analysis and interpretation; was involved in critically revising the manuscript; and read and approved the final manuscript. AE made substantial contributions to conception, design, and data analysis and interpretation; was involved in critically revising the manuscript; and read and approved the final manuscript. 


\section{Acknowledgements}

The authors thank Allergan, Inc., for funding Imprint Publication Science, New York, NY, to provide editorial support in the preparation and styling of this manuscript.

\section{Author details}

${ }^{1}$ Epidemiology \& Database Analytics, United BioSource Corporation, Lexington, MA, USA. ${ }^{2}$ Neurosciences, Medical Affairs, Allergan, Inc., Irvine, CA, USA. ${ }^{3}$ Health Economics and Epidemiology, Evidera, Lexington, MA, USA. ${ }^{4}$ Rehabilitation Medicine, Mount Washington Pediatric Hospital, Baltimore, MD, USA. ${ }^{5}$ Rehabilitation Medicine, NIH, Bethesda, MD, USA. ${ }^{6}$ Gait \& Motion Analysis Laboratory, MossRehab \& Albert Einstein Medical Center, Elkins Park, PA, USA.

Received: 16 August 2012 Accepted: 3 September 2013 Published: 8 September 2013

\section{References}

1. Lance JW: The control of muscle tone, reflexes, and movement: Robert Wartenberg Lecture. Neurology 1980, 30(12):1303-1313.

2. Bergfeldt U, Borg K, Kullander K, Julin P: Focal spasticity therapy with botulinum toxin: effects on function, activities of daily living and pain in 100 adult patients. J Rehabil Med 2006, 38(3):166-171.

3. Mostoufi SA: Spasticity and its management. Pain Manage Rounds 2005, 2(5):1-6.

4. Esquenazi A: Improvements in healthcare and cost benefits associated with botulinum toxin treatment of spasticity and muscle overactivity. Eur J Neurol 2006, 13(Suppl 4):27-34.

5. O'Brien CF: Treatment of spasticity with botulinum toxin. Clin J Pain 2002, 18(6 Suppl):S182-S190.

6. Esquenazi A: Falls and fractures in older post-stroke patients with spasticity: consequences and drug treatment considerations. Clin Geriatr 2004, 12(8):27-35.

7. Simpson DM, Gracies JM, Graham HK, Miyasaki JM, Naumann M, Russman B, Simpson LL, So Y: Assessment: botulinum neurotoxin for the treatment of spasticity (an evidence-based review): report of the therapeutics and technology assessment subcommittee of the American academy of neurology. Neurology 2008, 70(19):1691-1698.

8. Yelnik AP, Simon O, Parratte B, Gracies JM: How to clinically assess and treat muscle overactivity in spastic paresis. J Rehabil Med 2010, 42(9):801-807.

9. Brainin M, Norrving B, Sunnerhagen KS, Goldstein LB, Cramer SC, Donnan GA, Duncan PW, Francisco G, Good D, Graham G, et al: Poststroke chronic disease management: towards improved identification and interventions for poststroke spasticity-related complications. Int I Stroke 2011, 6(1):42-46

10. Bhakta BB: Management of spasticity in stroke. Br Med Bull 2000, 56(2):476-485.

11. Ryu JS, Lee JW, Lee SI, Chun MH: Factors predictive of spasticity and their effects on motor recovery and functional outcomes in stroke patients. Top Stroke Rehabil 2010, 17(5):380-388.

12. Thompson AJ, Jarrett L, Lockley L, Marsden J, Stevenson VL: Clinical management of spasticity. J Neurol Neurosurg Psychiatry 2005, 76(4):459-463.

13. Woldag $\mathrm{H}$, Hummelsheim $\mathrm{H}$ : Is the reduction of spasticity by botulinum toxin a beneficial for the recovery of motor function of arm and hand in stroke patients? Eur Neurol 2003, 50(3):165-171.

14. Albanese A: Terminology for preparations of botulinum neurotoxins: what a difference a name makes. JAMA 2011, 305(1):89-90.

15. Product Correspondence - Final SPL for approved BLA STN 103000/5189: [http:// www.accessdata.fda.gov/drugsatfda_docs/appletter/2010/103000s5189/tr.pdf]

16. Cook DJ, Mulrow CD, Haynes RB: Systematic reviews: synthesis of best evidence for clinical decisions. Ann Intern Med 1997, 126(5):376-380.

17. Higgins J, Green S: Cochrane Handbook for Systematic Reviews of Interventions 4.2.1 [updated December 2003]. Chichester, UK: John Wiley \& Sons, Ltd; 2004.

18. Kirazli Y, On AY, Kismali B, Aksit R: Comparison of phenol block and botulinus toxin type $A$ in the treatment of spastic foot after stroke: a randomized, double-blind trial. Am J Phys Med Rehabil 1998, 77(6):510-515.

19. On AY, Kirazli Y, Kismali B, Aksit R: Mechanisms of action of phenol block and botulinus toxin Type A in relieving spasticity: electrophysiologic investigation and follow-up. Am J Phys Med Rehabil 1999, 78(4):344-349.
20. Lagalla G, Danni M, Reiter F, Ceravolo MG, Provinciali L: Post-stroke spasticity management with repeated botulinum toxin injections in the upper limb. Am J Phys Med Rehabil 2000, 79(4):377-384. quiz 391-374.

21. Reiter F, Danni M, Ceravolo MG, Provinciali L: Disability changes after treatment of upper limb spasticity with botulinum toxin. Neurorehabilitation and Neural Repair 1996, 10(1):47-52.

22. Chen JJ, Wu YN, Huang SC, Lee HM, Wang YL: The use of a portable muscle tone measurement device to measure the effects of botulinum toxin type a on elbow flexor spasticity. Arch Phys Med Rehabil 2005, 86(8):1655-1660.

23. Lee HM, Chen JFJ, Wu YN, Wang YL, Huang SC, Piotrkiewicz M: Time course analysis of the effects of botulinum toxin type A on elbow spasticity based on biomechanic and electromyographic parameters. Archives of Physical Medicine and Rehabilitation 2008, 89(4):692-699.

24. Rousseaux M, Buisset N, Daveluy W, Kozlowski O, Blond S: Comparison of botulinum toxin injection and neurotomy in patients with distal lower limb spasticity. Eur J Neurol 2008, 15(5):506-511.

25. Rousseaux M, Compere S, Launay MJ, Kozlowski O: Variability and predictability of functional efficacy of botulinum toxin injection in leg spastic muscles. J Neurol Sci 2005, 232(1-2):51-57.

26. Albani G, Cimolin V, Galli M, Vimercati S, Bar D, Campanelli L, Gandolfi R Lombardi R, Mauro A: Use of surface EMG for evaluation of upper limb spasticity during botulinum toxin therapy in stroke patients. Funct Neurol 2010, 25(2):103-107.

27. Bayram S, Sivrioglu K, Karli N, Ozcan O: Low-dose botulinum toxin with short-term electrical stimulation in poststroke spastic drop foot: a preliminary study. Am J Phys Med Rehabil 2006, 85(1):75-81.

28. Bhakta BB, Cozens JA, Bamford JM, Chamberlain MA: Use of botulinum toxin in stroke patients with severe upper limb spasticity. J Neurol Neurosurg Psychiatry 1996, 61(1):30-35.

29. Brashear A, Gordon MF, Elovic E, Kassicieh VD, Marciniak C, Do M, Lee CH, Jenkins S, Turkel C: Intramuscular injection of Botulinum toxin for the treatment of wrist and finger spasticity after a stroke. N Engl J Med 2002, 347(6):395-400

30. Carda S, Molteni F: Taping versus electrical stimulation after Botulinum toxin type A injection for wrist and finger spasticity. A case-control study. Clin Rehabil 2005, 19(6):621-626.

31. Childers MK, Brashear A, Jozefczyk P, Reding M, Alexander D, Good D, Walcott JM, Jenkins SW, Turkel C, Molloy PT: Dose-dependent response to intramuscular Botulinum toxin type A for upper-limb spasticity in patients after a stroke. Arch Phys Med Rehabil 2004, 85(7):1063-1069.

32. Childers MK, Stacy M, Cooke DL, Stonnington HH: Comparison of two injection techniques using Botulinum toxin in spastic hemiplegia. Am J Phys Med Rehabil 1996, 75(6):462-469.

33. de Boer KS, Arwert HJ, de Groot JH, Meskers CGM, Mishre ADR, Arendzen $\mathrm{JH}$ : Shoulder pain and external rotation in spastic hemiplegia do not improve by injection of Botulinum toxin $\mathrm{A}$ into the subscapular muscle. Journal of Neurology Neurosurgery and Psychiatry 2008, 79(5):581-583.

34. Dunne JW, Heye N, Dunne SL: Treatment of chronic limb spasticity with Botulinum toxin A. J Neurol Neurosurg Psychiatry 1995, 58(2):232-235.

35. Esquenazi A, Mayer N, Garreta R: Influence of Botulinum toxin type A treatment of elbow flexor spasticity on hemiparetic gait. American Journal of Physical Medicine \& Rehabilitation 2008, 87(4):305-310.

36. Farina S, Migliorini C, Gandolfi M, Bertolasi L, Casarotto M, Manganotti P, Fiaschi A, Smania N: Combined effects of Botulinum toxin and casting treatments on lower limb spasticity after stroke. Funct Neurol 2008, 23(2):87-91

37. Fock J, Galea MP, Stillman BC, Rawicki B, Clark M: Functional outcome following Botulinum toxin $A$ injection to reduce spastic equinus in adults with traumatic brain injury. Brain Inj 2004, 18(1):57-63.

38. Francisco GE, Boake C, Vaughn A: Botulinum toxin in upper limb spasticity after acquired brain injury: a randomized trial comparing dilution techniques. Am J Phys Med Rehabil 2002, 81(5):355-363.

39. Giovannelli M, Borriello G, Castri P, Prosperini L, Pozzilli C: Early physiotherapy after injection of Botulinum toxin increases the beneficial effects on spasticity in patients with multiple sclerosis. Clin Rehabil 2007, 21(4):331-337.

40. Girlanda P, Quartarone A, Sinicropi S, Nicolosi C, Roberto ML, Picciolo G, Macaione V, Battaglia F, Ruggeri M, Messina C: Botulinum toxin in upper limb spasticity: study of reciprocal inhibition between forearm muscles. Neuroreport 1997, 8(14):3039-3044. 
41. Gracies JM, Lugassy M, Weisz DJ, Vecchio M, Flanagan S, Simpson DM: Botulinum toxin dilution and endplate targeting in spasticity: a double-blind controlled study. Archives of Physical Medicine and Rehabilitation 2009, 90(1):9-16.

42. Grazko MA, Polo KB, Jabbari B: Botulinum toxin A for spasticity, muscle spasms, and rigidity. Neurology 1995, 45(4):712-717.

43. Hecht MJ, Stolze H, Auf Dem Brinke M, Giess R, Treig T, Winterholler M, Wissel J: Botulinum neurotoxin type $A$ injections reduce spasticity in mild to moderate hereditary spastic paraplegia - report of 19 cases. Movement Disorders 2008, 23(2):228-233.

44. Henzel MK, Munin MC, Niyonkuru C, Skidmore ER, Weber DJ, Zafonte RD: Comparison of surface and ultrasound localization to identify forearm flexor muscles for Botulinum toxin injections. PM R 2010, 2(7):642-646.

45. Hesse S, Krajnik J, Luecke D, Jahnke MT, Gregoric M, Mauritz KH: Ankle muscle activity before and after Botulinum toxin therapy for lower limb extensor spasticity in chronic hemiparetic patients. Stroke 1996, 27(3):455-460

46. Hesse S, Lucke D, Malezic M, Bertelt C, Friedrich H, Gregoric M, Mauritz KH: Botulinum toxin treatment for lower limb extensor spasticity in chronic hemiparetic patients. J Neurol Neurosurg Psychiatry 1994, 57(11):1321-1324.

47. Jahangir AW, Tan HJ, Norlinah MI, Nafisah WY, Ramesh S, Hamidon BB, Raymond AA: Intramuscular injection of Botulinum toxin for the treatment of wrist and finger spasticity after stroke. Medical Journal of Malaysia 2007, 62(4):319-322.

48. Kaji R, Osako Y, Suyama K, Maeda T, Uechi $Y$, Iwasaki M: Botulinum toxin type A in post-stroke upper limb spasticity. Curr Med Res Opin 2010, 26(8):1983-1992

49. Kaji R, Osako Y, Suyama K, Maeda T, Uechi Y, Iwasaki M: Botulinum toxin type A in post-stroke lower limb spasticity: a multicenter, double-blind, placebo-controlled trial. J Neurol 2010, 257(8):1330-1337.

50. Karadag-Saygi E, Cubukcu-Aydoseli K, Kablan N, Ofluoglu D: The role of kinesiotaping combined with Botulinum toxin to reduce plantar flexors spasticity after stroke. Topics in Stroke Rehabilitation 2010, 17(4):318-322.

51. Khamees MF, Kondeva M, Eyadeh AA, Karar AH: Our experience with intramuscular injections of Botulinum toxin $A$ for the treatment of upper limb flexors spasticity after stroke. Kuwait Med J 2004, 36(2):117-121.

52. Levy CE, Giuffrida C, Richards L, Wu S, Davis S, Nadeau SE: Botulinum toxin a, evidence-based exercise therapy, and constraint-induced movement therapy for upper-limb hemiparesis attributable to stroke: a preliminary study. Am J Phys Med Rehabil 2007, 86(9):696-706.

53. Lim EC, Ong BK, Seet RC: Botulinum toxin-A injections for spastic toe clawing. Parkinsonism Relat Disord 2006, 12(1):43-47.

54. Lim JY, Koh JH, Paik NJ: Intramuscular Botulinum toxin-A reduces hemiplegic shoulder pain: A randomized, double-blind, comparative study versus intraarticular triamcinolone acetonide. Stroke 2008, 39(1):126-131.

55. Link A, Kabus C, Haas J: Use of spasmography to assess the effects of Botulinum toxin type $A$ in patients with lower-limb spasticity. European Journal of Neurology 1999, 6(SUPPL. 4):S69-S73.

56. Maanum G, Jahnsen R, Stanghelle JK, Sandvik L, Keller A: Effects of Botulinum toxin $A$ in ambulant adults with spastic cerebral palsy: a randomized double-blind placebo controlled-trial. J Rehabil Med 2011, 43(4):338-347

57. Manca M, Merlo A, Ferraresi G, Cavazza S, Marchi P: Botulinum toxin type A versus phenol. A clinical and neurophysiological study in the treatment of ankle clonus. Eur J Phys Rehabil Med 2010, 46(1):11-18.

58. Mancini F, Sandrini G, Moglia A, Nappi G, Pacchetti C: A randomised, double-blind, dose-ranging study to evaluate efficacy and safety of three doses of Botulinum toxin type $A$ (Botox) for the treatment of spastic foot. Neurol Sci 2005, 26(1):26-31.

59. Marciniak C, Rader L, Gagnon C: The use of Botulinum toxin for spasticity after spinal cord injury. American Journal of Physical Medicine \& Rehabilitation 2008, 87(4):312-317.

60. Mayer NH, Whyte J, Wannstedt G, Ellis CA: Comparative impact of 2 Botulinum toxin injection techniques for elbow flexor hypertonia. Arch Phys Med Rehabil 2008, 89(5):982-987.

61. Miscio G, Del Conte C, Pianca D, Colombo R, Panizza M, Schieppati M, Pisano F: Botulinum toxin in post-stroke patients: stiffness modifications and clinical implications. J Neurol 2004, 251(2):189-196.

62. Mohammadi B, Balouch SA, Dengler R, Kollewe K: Long-term treatment of spasticity with Botulinum toxin type $A$ : an analysis of 1221 treatments in 137 patients. Neurol Res 2010, 32(3):309-313.

63. Molteni F: Botulinum toxin and rehabilitation programs in lower limb spasticity. Eur J Neurol 1995, 2(3):61-67.
64. Novak AC, Olney SJ, Bagg S, Brouwer B: Gait changes following Botulinum toxin A treatment in stroke. Top Stroke Rehabil 2009, 16(5):367-376.

65. Opara J, Hordynska E, Swoboda A: Effectiveness of Botulinum toxin A in the treatment of spasticity of the lower extremities in adults preliminary report. Ortop Traumatol Rehabil 2007, 9(3):277-285.

66. Pandyan AD, Vuadens P, van Wijck FM, Stark S, Johnson GR, Barnes MP: Are we underestimating the clinical efficacy of Botulinum toxin (type A)? Quantifying changes in spasticity, strength and upper limb function after injections of Botox to the elbow flexors in a unilateral stroke population. Clin Rehabil 2002, 16(6):654-660.

67. Panizza M, Castagna M, di Summa A, Saibene L, Grioni G, Nilsson J: Functional and clinical changes in upper limb spastic patients treated with Botulinum toxin (BTX). Funct Neurol 2000, 15(3):147-155.

68. Pedreira G, Cardoso E, Melo A: Botulinum toxin type A for refractory post-stroke shoulder pain. Arq Neuropsiquiatr 2008, 66(2A):213-215.

69. Reiter F, Danni M, Lagalla G, Ceravolo G, Provinciali L: Low-dose Botulinum toxin with ankle taping for the treatment of spastic equinovarus foot after stroke. Arch Phys Med Rehabil 1998, 79(5):532-535.

70. Restivo DA, Tinazzi M, Patti F, Palmeri A, Maimone D: Botulinum toxin treatment of painful tonic spasms in multiple sclerosis. Neurology 2003, 61(5):719-720

71. Richardson D, Sheean G, Werring D, Desai M, Edwards S, Greenwood R, Thompson A: Evaluating the role of Botulinum toxin in the management of focal hypertonia in adults. J Neurol Neurosurg Psychiatry 2000, 69(4):499-506.

72. Robertson JVG, Pradon D, Bensmail D, Fermanian C, Bussel B, Roche N: Relevance of Botulinum toxin injection and nerve block of rectus femoris to kinematic and functional parameters of stiff knee gait in hemiplegic adults. Gait \& Posture 2009, 29(1):108-112.

73. Rousseaux M, Kozlowski O, Froger J: Efficacy of Botulinum toxin A in upper limb function of hemiplegic patients. J Neurol 2002, 249(1):76-84.

74. Sampaio C, Ferreira JJ, Pinto AA, Crespo M, Ferro JM, Castro-Caldas A: Botulinum toxin type $A$ for the treatment of arm and hand spasticity in stroke patients. Clin Rehabil 1997, 11(1):3-7.

75. Simpson DM, Alexander DN, O'Brien CF, Tagliati M, Aswad AS, Leon JM, Gibson J, Mordaunt JM, Monaghan EP: Botulinum toxin type A in the treatment of upper extremity spasticity: a randomized, double-blind, placebo-controlled trial. Neurology 1996, 46(5):1306-1310.

76. Simpson DM, Gracies JM, Yablon SA, Barbano R, Brashear A: Botulinum neurotoxin versus tizanidine in upper limb spasticity: a placebo-controlled study. J Neurol Neurosurg Psychiatry 2009, 80(4):380-385.

77. Slawek J, Bogucki A, Reclawowicz D: Botulinum toxin type A for upper limb spasticity following stroke: an open-label study with individualised, flexible injection regimens. Neurol Sci 2005, 26(1):32-39.

78. Snow BJ, Tsui JK, Bhatt MH, Varelas M, Hashimoto SA, Calne DB: Treatment of spasticity with Botulinum toxin: a double-blind study. Ann Neurol 1990, 28(4):512-515

79. Stampacchia G, Bradaschia E, Rossi B: Change of stretch reflex threshold in spasticity: effect of Botulinum toxin injections. Arch Ital Biol 2004, 142(3):265-273.

80. Stoquart GG, Detrembleur C, Palumbo S, Deltombe T, Lejeune TM: Effect of Botulinum toxin injection in the rectus femoris on stiff-knee gait in people with stroke: A prospective observational study. Archives of Physical Medicine and Rehabilitation 2008, 89(1):56-61.

81. Suputtitada A: Local Botulinum toxin type $A$ injections in the treatment of spastic toes. Am J Phys Med Rehabil 2002, 81(10):770-775.

82. Trompetto C, Bove M, Avanzino L, Francavilla G, Berardelli A, Abbruzzese G. Intrafusal effects of Botulinum toxin in post-stroke upper limb spasticity. European Journal of Neurology 2008, 15(4):367-370.

83. Turhanoglu AD, Karabulut Z, Bayram H, Turhanoglu S, Erdogan F, Apak I, Yayla V: Botulinum toxin $A$ in the treatment of spasticity - An open label study. Journal of Back and Musculoskeletal Rehabilitation 2002, 16(2-3):51-56.

84. Turkel CC, Bowen B, Liu J, Brin MF: Pooled analysis of the safety of Botulinum toxin type $A$ in the treatment of poststroke spasticity. Arch Phys Med Rehabil 2006, 87(6):786-792.

85. Verplancke D, Snape S, Salisbury CF, Jones PW, Ward AB: A randomized controlled trial of Botulinum toxin on lower limb spasticity following acute acquired severe brain injury. Clin Rehabil 2005, 19(2):117-125.

86. Wang HC, Hsieh LF, Chi WC, Lou SM: Effect of intramuscular Botulinum toxin injection on upper limb spasticity in stroke patients. Am J Phys Med Rehabil 2002, 81(4):272-278.

87. Weber DJ, Skidmore ER, Niyonkuru C, Chang CL, Huber LM, Munin MC: Cyclic functional electrical stimulation does not enhance gains in hand 
grasp function when used as an adjunct to onaBotulinumtoxinA and task practice therapy: a single-blind, randomized controlled pilot study. Arch Phys Med Rehabil 2010, 91(5):679-686.

88. Yaar E, Tok F, Safaz I, Balaban B, Yilmaz B, Alaca R: The efficacy of serial casting after Botulinum toxin type $A$ injection in improving equinovarus deformity in patients with chronic stroke. Brain Injury 2010, 24(5):736-739.

89. Yablon $S A$, Agana $B T$, Ivanhoe $C B$, Boake $C$ : Botulinum toxin in severe upper extremity spasticity among patients with traumatic brain injury: an open-labeled trial. Neurology 1996, 47(4):939-944.

90. Yelnik AP, Colle FM, Bonan IV, Lamotte DR: Disabling overactivity of the extensor hallucis longus after stroke: clinical expression and efficacy of Botulinum toxin type A. Arch Phys Med Rehabil 2003, 84(1):147-149.

doi:10.1186/1471-2377-13-118

Cite this article as: Nalysnyk et al:: OnabotulinumtoxinA muscle injection patterns in adult spasticity: a systematic literature review. BMC Neurology 2013 13:118.

\section{Submit your next manuscript to BioMed Central and take full advantage of:}

- Convenient online submission

- Thorough peer review

- No space constraints or color figure charges

- Immediate publication on acceptance

- Inclusion in PubMed, CAS, Scopus and Google Scholar

- Research which is freely available for redistribution 